\title{
Optimal Selection of Equipment for Injection Molding Process using the AHP Method
}

\author{
Adelina Hrițuc ${ }^{1}$, Margareta Coteață ${ }^{1, *}$, Oana Dodun ${ }^{1}$, Gheorghe Nagîț ${ }^{1}$, and Laurențiu \\ Slătineanu ${ }^{1}$ \\ 1"Gheorghe Asachi" Technical University of Iaşi, Department of Machine Manufacturing \\ Technology, Blvd. D. Mangeron, 59 A, 700050 Iaşi, Romania
}

\begin{abstract}
Increased interest in the study of plastics has led to the development of processing technologies using such materials. The variety of plastics has led to a diversification of the technical processes through which the finished plastic products can be obtained. We approached the idea of designing plastic injection equipment, considering that various research could be made on the phenomena involved during the process, as well as the observation of the technological properties of the plastics. To design such equipment, some known methods used in conception processes could be applied. Optimizing the equipment design process is one of the elements that can ensure high efficiency of the entire injection molding process. Thus, the method chosen in this case was the analytic hierarchy process (AHP) method, which is one of the methods that offer the possibility to choose a solution when there are many alternatives. The relative simplicity and precision of this method are some of the arguments behind this method. The combination of required equipment and application of the AHP method allowed the choice of an optimal solution for testing injection molding. The result of design activity was an alternative to equipment that can be used for developing future research.
\end{abstract}

\section{Introduction}

Plastics are non-metallic materials generally characterized by an amorphous structure and that could be obtained by melting together several constituents such as resins, fillers, plasticizers, dyes, auxiliary materials etc.). These material have the propriety to be easily modeled, due to their high plasticity in the temperature interval $140^{\circ}-180^{\circ} \mathrm{C}$.

Plastic products can be manufactured using various processing methods. One of these processing methods is injection molding. Essentially, the injection molding supposes the melting of the plastic at a certain temperature and subsequently, the melted material is pressed through a nozzle in a cavity of a mold; after cooling, a part that has the mold cavity shape is obtained. In principle, the injection molding process is efficient in the case of high series or mass production, due to its high productivity. A disadvantage of the injection molding process is the relatively high price of the mold and of the injection molding equipment. To apply the injection molding process in the case of a certain plastic part, some

*Corresponding author: mcoteata@tcm.tuiasi.ro 
information concerning the processability of the plastic material by injection molding has to be known.

In the Department of Machine Manufacturing Technology from the "Gheorghe Asachi" Technical University of Iași, the problem of designing equipment for the investigation of the characteristics of the injection molding process was approached.

Over the years, impressive efforts were invested in the better knowledge of the plastic materials ability to be processed by the injection molding process.

Thus, Reig et al. considered that to increase the volume of the recycled products, it is important to have more information concerning the processability of distinct blends including recycled materials [1]. They developed research aiming to determine and apply optimal processes of plastic materials recycling. They considered that a material processability index of the blends could be defined and used.

The problem of processability of polyoxymethylene in powder injection molding was approached by Gonzalez-Gutierrez et al., considering this material as a high-performance engineering material [2]. They developed an investigation concerning the influence exerted by the binder viscosity on certain mechanical properties of the plastic material.

Huang et al. proposed an apparatus for developing an injection molding process based on the use of a capillary rheometer [3]. They considered that the apparatus facilitates also the monitoring of the injection flow process.

The objective of the research presented in this paper was to emphasize the possibility of using the so-called analytic hierarchy process in the selection of a certain solution for equipment intended to allow the evaluation of the plastics processability by injection molding.

\section{Theoretical considerations}

The process of injection molding could be considered as a complex process. As abovementioned, initially, the plastic material must be heated up to a temperature at which it arrives in a plastic state that facilitates its pressing and penetration into the mold cavity. If the mold walls found in contact with the melted plastic is cold, an immediate increase of the plastic viscosity is expected and just a solidification process could appear.

On the other hand, it is important that the plastic is characterized at least by good processability by plastic injection. This means that among other requests, the plastic must maximally maintain its capacity to fill the cavity that exists into the injection mold. Taking the idea applied to evaluate the metallic material processability by casting, when a spiralshaped part is used, the possibility of evaluating the plastic ability to fill a spiral channel performed in a special mold was considered. To simplify the testing conditions and simultaneously to ensure the same experimental conditions when repeating the experimental tests, on supposed that the pressing of the melted plastic could be materialized under the action of the weight of pre-established size.

Once defined an idea concerning the functional requirements corresponding to equipment for testing the plastic ability to be processed by injection molding, there was necessary to define adequate equipment able to ensure the plastic melting and its advancing to the nozzle and subsequently to the special mold in which a spiral groove exists.

When developing a research activity aiming to establish the principle structure of this equipment, one found that various solutions able to answer the pre-established functional requirements were identified. Three such solutions were presented in figure 1 . One could see that the first alternative $(A 1)$ supposes a vertical cylinder in which a piston could move under the action of a weight placed on a plate, while an electric resistance placed at the bottom of the cylinder could determine the plastic melting before it is pressed to the special mold. A second alternative $(A 2)$ could use a shaft with a spiral protrusion whose rotation 
could also press the plastic material introduced as a powder in the horizontal cylinder zone where it is heated and subsequently pressed to the injection nozzle. A third alternative $(A 3)$ could suppose the use of a vertical cylinder where the plastic material is pressed by a piston acted by a rack. This rack is rectilinearly moved by a gear rotated as a consequence of a weight placed on a plate found at the end of a cable wrapped on a wheel coaxially positioned with the gear.

To choose the version of equipment intended to be performed and tested, many selection methods could be applied. One noticed that this is the case of developing a multicriterial decision since distinct criteria could be considered during the selection process.

One found that various methods could be applied when a problem of the multicriterial decision must be solved.

One of such methods is the so-called analytic hierarchy process $(A H P)$. The method was proposed by the professor Thomas A. Saaty in ' 70 years of the previous century and from that time, many scientific studies and applications were made. When applying the AHP method, the problems corresponding to certain stages must be successively solved [48].

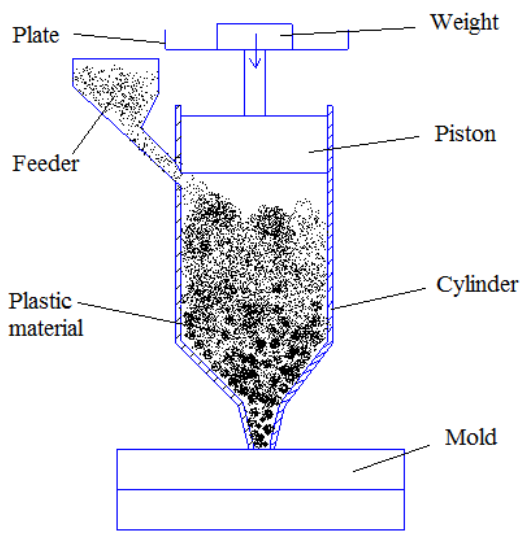

Alternative 1

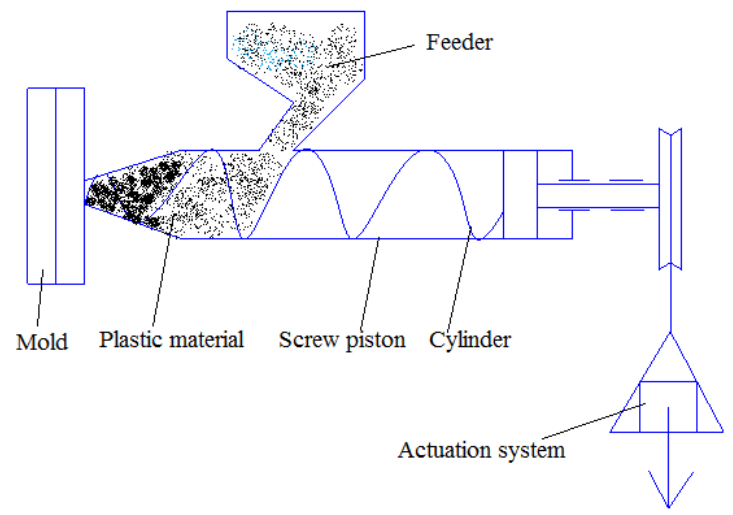

Alternative 2

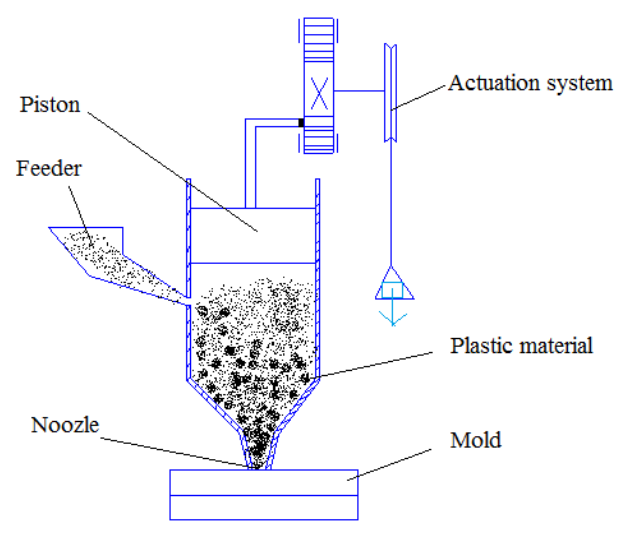

Alternative 3

Fig. 1. Alternatives considered for equipment intended to be used to evaluate the plastic processability by injection molding. 
Considering only the scientific researches concerning the use of the AHP method in the case of plastics, one found that AlKaabneh et al. used a combination of $A H P$ process and Taguchi experimental design to establish the values for the injection molding process input factors [4].

Chen and Huang integrated $A H P$ and Taguchi method to emphasize the factors able to influence the injection molding warpage [5]. They concluded that certain combinations of the values corresponding to the process input factors could ensure minimal warpage.

A version of fuzzy- $A H P$ methodology was used by Nagahanumaiah et al. in the evaluation of rapid tooling manufacturability in the case of an injection mold [6]. They appreciated that the proposed methodology facilitates introducing a minor modification of the mold design when the problem of improving the mold manufacturability cost is stated.

\section{Use of AHP method in selection a solution in the case of equipment for testing the plastic processability by injection molding}

To apply the AHP method in the process of selecting the solution for the equipment intended to be used in the investigation of the plastic processability by plastic injection, the problems corresponding to several stages were gradually approached and solved.

Thus, to better define/model the problem, the above-mentioned research objective was defined. One considered also that the three alternatives for the desired equipment abovedefined could be the subjects of the analysis.

The criteria for the evaluation of these alternatives could be the followings: $C 1$ :

Table 1. Comparison of two by two criteria and establishing of differentiating marks.

\begin{tabular}{|c|c|c|c|c|c|c|c|c|c|c|c|c|c|c|}
\hline $\begin{array}{l}\text { Line } \\
\text { no. } 1\end{array}$ & \multicolumn{5}{|c|}{$A$ is more important than $B ?$} & $\begin{array}{l}\text { Equa- } \\
\text { lity }\end{array}$ & \multicolumn{8}{|c|}{$\begin{array}{l}\text { How many times it is } \\
\text { important }\end{array}$} \\
\hline 2 & & $A$ & or & & $B$ & 1 & 2 & 3 & 4 & 5 & 6 & 7 & 8 & 9 \\
\hline $\begin{array}{c}\text { Line } \\
\text { no. } 3 \\
\text { Co- } \\
\text { lumn } \\
\text { no.1 }\end{array}$ & 2 & 3 & 4 & 5 & 6 & 7 & 8 & 9 & 10 & 11 & 12 & 13 & 14 & 15 \\
\hline $\begin{array}{l}\text { Line } \\
\text { no. } 4\end{array}$ & & Simplicity $(C 1)$ & or & & Accessibility $(C 2)$ & $X$ & & & & & & & & \\
\hline 5 & $X$ & Simplicity $(C 1)$ & or & & $\begin{array}{c}\text { Experimental } \\
\text { conditions }(C 3)\end{array}$ & & $X$ & & & & & & & \\
\hline 6 & & Simplicity $(C 1)$ & or & $X$ & Novelty $(C 4)$ & & & $X$ & & & & & & \\
\hline 7 & $X$ & Accessibility $(C 2)$ & or & & $\begin{array}{c}\text { Experimental } \\
\text { conditions }(C 5)\end{array}$ & & $X$ & & & & & & & \\
\hline 8 & & $\begin{array}{l}\text { Accessibility } \\
(C 2)\end{array}$ & or & $X$ & Novelty $(C 3)$ & & $X$ & & & & & & & \\
\hline 9 & & $\begin{array}{l}\text { Experimental } \\
\text { conditions }(C 3)\end{array}$ & or & $X$ & Novelty $(C 4)$ & & $X$ & & & & & & & \\
\hline
\end{tabular}

constructive simplicity (abbreviation: simplicity); $C 2$ : possibility to perform equipment using the available machine tools and materials (abbreviation: accessibility); $C 3$ : possibility to develop scientific research by changing the experimental conditions (abbreviation: experimental conditions); $C 5$ : the novelty of the solution (abbreviation: novelty). 
To determine the distinct values involved by the applying of the AHP method, the software proposed in [7] was used.

A second stage refers to the so-called establishment of priorities. With this aim in view, the selected criteria are compared two by two and considering the following evaluation scale: 1 - criteria of equal importance, 3 - criterium of moderate importance, 5 - high importance, 7 - very high importance, 9 - extremely high importance. The results of the comparisons were included in table 1.

In correlation with the comparison of the criteria two by two, a so-called decision matrix could be elaborated; the information corresponding to this decision matrix was included in the columns nos. 3-6 from table 2.

The number $N_{c}$ of the necessary comparisons could be determined by means of the relation:

$$
N_{c}=n(n-1) / 2 \text {, }
$$

where $n$ is the number of criteria.

Table 2. Decision matrix, weightings, and ranks corresponding to the used criteria.

\begin{tabular}{|c|c|c|c|c|c|c|c|}
\hline \multicolumn{2}{|c|}{ Criterion } & $\boldsymbol{C 1}$ & $\boldsymbol{C 2}$ & $\boldsymbol{C 3}$ & $\boldsymbol{C 4}$ & Priority & Rank \\
\hline $\begin{array}{r}\text { Column } \\
\text { no. } \mathbf{1}\end{array}$ & 2 & 3 & 4 & 5 & 6 & 7 & 8 \\
\hline $\boldsymbol{C 1}$ & Simplicity & 1 & 1.00 & 2.00 & 0.33 & $20.7 \%$ & 3 \\
\hline $\boldsymbol{C 2}$ & Accessibility & 1.00 & 1 & 2.00 & 0.50 & $22.4 \%$ & 2 \\
\hline $\boldsymbol{C 3}$ & Experimental conditions & 0.50 & 050 & 1 & 0.50 & $13.8 \%$ & 4 \\
\hline $\boldsymbol{C 4}$ & Novelty & 3.00 & 2.00 & 2.00 & 1 & $43.1 \%$ & 1 \\
\hline
\end{tabular}

In another stage of applying the $A H P$ method, all the considered alternatives are compared two by two by taking into consideration each evaluation criteria. In this way, priority weightings of all the criteria and their ranks could be highlighted. The values for priority weightings and ranks thus obtained were included in tables 3, 4, 5 and 6.

Table 3. Results of comparing two by two of the 3 available alternatives when using the criterion C1 (Simplicity).

\begin{tabular}{|c|c|c|c|c|c|}
\hline Alternative & $\boldsymbol{A 1}$ & $\boldsymbol{A 2}$ & $\boldsymbol{A 3}$ & $\begin{array}{c}\text { Priority } \\
\text { vector }\end{array}$ & Rank \\
\hline$A 1$ & 1 & 2.00 & 3.00 & $55.0 \%$ & 1 \\
\hline$A 2$ & 0.5 & 1 & 1.00 & $24.0 \%$ & 2 \\
\hline$A 3$ & 0.33 & 1.00 & 1 & $21.0 \%$ & 3 \\
\hline
\end{tabular}

Table 4. Results of comparing two by two of the 3 available alternatives when using the criterion C2 (Accessibility).

\begin{tabular}{|c|c|c|c|c|c|}
\hline Alternative & $\boldsymbol{A 1}$ & $\boldsymbol{A 2}$ & $\boldsymbol{A 3}$ & $\begin{array}{c}\text { Priority } \\
\text { vector }\end{array}$ & Rank \\
\hline$A 1$ & 1 & 2.00 & 2.000 & $50 \% \%$ & 2 \\
\hline$A 2$ & 0.50 & 1 & 1.00 & $25 \% \%$ & 3 \\
\hline$A 3$ & 0.50 & 1.00 & 1 & $25 \% \%$ & 1 \\
\hline
\end{tabular}

Table 5. Results of comparing two by two of the 3 available alternatives when using the criterion C3 (Experimental conditions).

\begin{tabular}{|c|c|c|c|c|c|}
\hline Alternative & $\boldsymbol{A 1}$ & $\boldsymbol{A 2}$ & $\boldsymbol{A 3}$ & $\begin{array}{c}\text { Priority } \\
\text { vector }\end{array}$ & Rank \\
\hline$A 1$ & 1 & 1.00 & 2.00 & $41.3 \%$ & 1 \\
\hline$A 2$ & 1.00 & 1 & 1.00 & $32.7 \%$ & 2 \\
\hline$A 3$ & 0.50 & 1.00 & 1 & $26.0 \%$ & 3 \\
\hline
\end{tabular}


Table 6. Results of comparing two by two of the 3 available alternatives when using the criterion $C 4$ (Novelty).

\begin{tabular}{|c|c|c|c|c|c|}
\hline Alternative & $\boldsymbol{A 1}$ & $\boldsymbol{A 2}$ & $\boldsymbol{A 3}$ & $\begin{array}{r}\text { Priority } \\
\text { vector }\end{array}$ & Rank \\
\hline$A 1$ & 1 & 2.00 & 3.00 & $55.0 \%$ & 1 \\
\hline$A 2$ & 0.50 & 1 & 1.00 & $24.0 \%$ & 2 \\
\hline$A 3$ & 0.33 & 1.00 & 1 & $21.0 \%$ & 3 \\
\hline
\end{tabular}

A general image concerning the criteria weightings and the importance of each alternative when a certain criterion is applied could be seen in table 7 . By considering the values included in table 7 , the general composite weighting could be determined using the sum of multiplications of the criterions' weightings with the values corresponding to each alternative when a certain criterion is used. The values thus obtained were included in the column no. 2-5 from table 7. On the base of these value, the final rank of the alternatives was established (column no. 7). In this way, one could notice that applying the $A H P$ method, the alternative $A 1$ could be considered as the most convenient when the abovementioned criteria are used [8].

Table 7. Evaluation of each alternative by means of each criterion.

\begin{tabular}{|c|c|c|c|c|c|c|}
\hline Criterion & $C 1$ & $C 2$ & C3 & $C 4$ & & Order \\
\hline $\begin{array}{ll} & \begin{array}{l}\text { Criterion } \\
\text { weight }\end{array} \\
\text { Alternative } & \\
\end{array}$ & 22.7 & 22.4 & 13.8 & 43.1 & $\begin{array}{c}\text { composite } \\
\text { weight }\end{array}$ & \\
\hline Column no. 1 & 2 & 3 & 4 & 5 & 6 & 7 \\
\hline$A 1$ & $55.0 \%$ & $50.0 \%$ & $41.3 \%$ & $55.0 \%$ & $53 \%$ & 3 \\
\hline$A 2$ & $24.0 \%$ & $25.0 \%$ & $32.7 \mathrm{O}$ & $24.0 \%$ & $25 \%$ & 2 \\
\hline$\overline{A 3}$ & $21.0 \%$ & $25.0 \%$ & 26.00 & 21.00 & $22 \%$ & 1 \\
\hline Sum & $100 \%$ & $100 \%$ & $100 \%$ & $100 \%$ & $100 \%$ & \\
\hline
\end{tabular}

Taking into consideration the above-mentioned considerations, equipment based on the use of a vertical column and the advance of the melted material under the action of a weight placed on a plate was designed and performed [9]. An image of this solution could be seen in figure 2 .

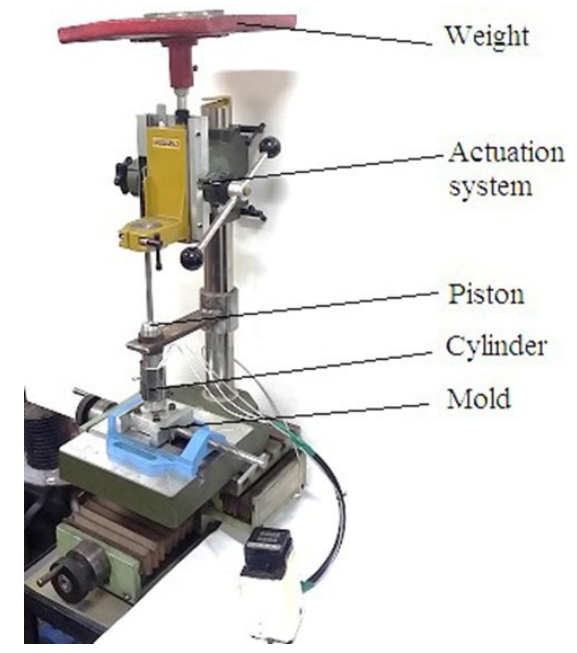

Fig. 2. Image of the equipment for testing the processability of plastics by injection molding. 


\section{Conclusions}

One of the methods applied in the case of necessity to solve a problem of multicriterial decision is the analytic hierarchy process. The method facilitates the optimal selection of an alternative among many available such alternatives and when certain evaluation criteria are previously established. This method was applied in the case of equipment for the evaluation of the plastics processability by molding injection. In this way and taking into consideration the values of the general composite weight that corresponds to each of the alternatives, a solution based on the use of a vertical cylinder and on pressing of the melted material under the action of a weight placed on a plate was selected and materialized.

In the future, there is the intention to develop some tests on the obtained equipment in order to evaluate the processability by injection of certain plastic materials.

\section{References}

1. M.J. Reig, V.J. Segui, S. Ferrandiz, and J.D. Zamanillo, J. Polym. Eng., 27(1), 27-54 (2007)

2. J. Gonzalez-Gutierrez, P. Oblak, B. S. von Bernstorff, I. Emri, Processability and mechanical properties of polyoxymethylene in powder injection molding, 2013 Annual Conference on Experimental and Applied Mechanics at Lombard, Illinois, USA, vol. 2 (2013)

3. Y.-G. Huang, D.-X. Li, and Y.-J. Liu, Exp. Techniques. 40(1), 137-148 (2016)

4. F.A.K. AlKaabneh · M. Barghash, I. Mishael, Int. J. Adv. Manuf. Technol. 49, 949959 (2013)

5. D.-C. Chen, C.-K. Huang, Advances in Technology Innovation, 1 (2), 46-49 (2016)

6. Nagahanumaiah, B. Ravi, N.P. Mukherjee, Int. J. Prod. Res., 45 (5) 1161-1181 (2007)

7. K.D. Gospel, AHP Online System - BPMSG. Multi-criteria Decision Making Using the Analytic Hierarchy Process, 2011, available: https://bpmsg.com/academic/, accessed: 5.05.2017

8. L. Slătineanu, M. Coteață, V. Dulgheru, P. Dușa, F. Banciu, I. Beșliu, The 11th International Conference on Axiomatic Design (ICAD 2017), MATEC Web Conf., vol. 127 (2017)

9. A. Hrițuc, 22nd International Conference on Innovative Manufacturing Engineering and Energy - IManE\&E 2018 MATEC Web Conf., vol. 178, 02001 (2018) 